\title{
A Triple-Band Low-Profile Planar Antenna for Wireless Applications
}

\author{
R. L. Li, B. Pan, T. Wu, J. Laskar, and M. M. Tentzeris \\ School of Electrical and Computer Engineering \\ Georgia Institute of Technology, Atlanta, GA 30332-0250, USA
}

\begin{abstract}
A triple-band low-profile planar antenna is developed for wireless applications. The triple-band planar antenna consists of a two-strip monopole for the 2-GHz band, a horizontal monopole for the $3.5-\mathrm{GHz}$ band, and a vertical monopole for the 5-GHz. The planar antenna is printed on a very thin substrate $(0.254 \mathrm{~mm}$ in thickness) with a very low profile ( $8 \mathrm{~mm}$ in height). The antenna achieves a bandwidth of $\sim 35 \%$ at the $2-\mathrm{GHz}$ band, $\sim 10 \%$ at the $3.5 \mathrm{GHz}$, and $\sim 15 \%$ at the $5-\mathrm{GHz}$ band, which may find applications in wireless/mobile devices.
\end{abstract}

\section{INTRODUCTION}

Recently, WiMAX (Worldwide Interoperability for Microwave Access) has become a fast-growing wireless technology that provides high-throughput broadband connections over long distances. The most likely spectrum allocation for WiMax standards (e.g., IEEE 802.16) will be around $3.5 \mathrm{GHz}$. Therefore, the future mobile devices should also include the 3.5-GHz band in addition to the 2-GHz band ( 30\%) for the DCS-1800 (DCS 1710-1880 MHz), PHS-1900 (1895-1918 MHz), PCS-1900 (1850-1990 MHz), IMT2000/UMTS (1885-2200 MHz) for mobile communications, and the 5-GHz UNII band $(\sim 12 \%)$ for wireless LANs $(5.15-5.875 \mathrm{GHz})$. This means that a triple-band antenna is desirable. In recent years, a lot of low-profile multi-band antennas have been developed for wireless applications [1]-[6]. Unfortunately, these multi-band antennas have a narrow bandwidth at the lower-frequency band and do not include the $3.5-\mathrm{GHz}$ band. In this paper, we present a triple-band low-profile planar antenna which can cover the $2-\mathrm{GHz}$ band, the $3.5-\mathrm{GHz}$ band, and the $5-\mathrm{GHz}$ band. The height of the antenna is only $8 \mathrm{~mm}$, which is suitable for a wireless mobile device.

\section{ANTENNA CONFIGURATION}

The configuration of a triple-band planar antenna is illustrated in Fig. 1. The design of the antenna is based on an RT/Duroid 5880 planar substrate that has a dielectric constant of $\varepsilon_{\mathrm{r}}=2.2$ and a thickness of $\mathrm{t}=10$ mils $(0.254 \mathrm{~mm})$. The triple-band antenna consists of a two-strip monopole for the $2-\mathrm{GHz}$ band, a horizontal monopole for the $3.5-\mathrm{GHz}$ band, and a vertical monopole for the 5-GHz band. The two-strip monopole is composed of an S-strip and a T-strip. The T-strip with the horizontal and vertical monopoles is printed on the front side of the Duroid The upper section (its width $=\mathrm{W}_{\mathrm{T}}$ and its height $=\mathrm{H}_{\mathrm{T}}$ ) of the $\mathrm{T}$ strip is fitted (leaving a space of $\mathrm{w}_{\mathrm{s}}$ ) into an area surrounded by the upper section (its width $=\mathrm{W}_{\mathrm{S}}$ ) of the S-strip (its strip width $=\mathrm{W}_{\mathrm{s}}$ ) while the lower section of the T-strip overlaps with the lower section of the S-strip, forming a two-strip line. The width of the two-strip line is equal to the width $\left(\mathrm{w}_{\mathrm{f}}\right)$ of the $50-\Omega$ microstrip line. The total height of the triple-band antenna is equal to the height $(\mathrm{H})$ of the two-strip monopole. The vertical monopole is equally divided into a wider upper part (its width $=\mathrm{W}_{\mathrm{U}}$ and its height $=\mathrm{H} / 2$ ) and a narrower lower part (its width $=\mathrm{W}_{\mathrm{L}}$ and its height $=\mathrm{H} / 2$ ) which is connected to the $50-\Omega$ microstrip line through a narrower microstrip line (its width $=\mathrm{W}_{\mathrm{c}}$ and its length is equal to the total width $\left(\mathrm{W}_{\mathrm{p}}\right)$ of the planar monopole). The horizontal monopole is formed by extending the lower section of the T-strip. The total width (W) of the triple-band 
antenna is equal to the sum of the widths of the two-strip monopole $\left(\mathrm{W}_{\mathrm{S}}\right)$ and the vertical monopole $\left(\mathrm{W}_{\mathrm{P}}\right)$, and the length $\left(\mathrm{L}_{\mathrm{H}}\right)$ of the horizontal monopole, i.e., $\mathrm{W}=\mathrm{W}_{\mathrm{S}}+\mathrm{W}_{\mathrm{P}}+\mathrm{L}_{\mathrm{H}}$. There is no direct electrical connection (e.g., by a shorting via) between the front side and the backside.

\section{RESULTS}

The triple-band planar antenna was simulated using the TLM (transmission line matrix) based design tool-MicroStripes 7.0. To verify the performance of the triple-band antennas, a prototype was fabricated and measured. The antenna was fabricated on a $10-$ mil-thick RT/Duroid 5880 substrate with 0.5 oz copper on both sides by wet etching process. This process is based on standard double-side lithography using Karl Suss MA-6 Mask Aligner which is capable of backside alignment. Some alignment markers were printed on both sides to aid the backside alignment. After the photoresist was patterned and developed on both sides, the unwanted copper was removed by the $30 \% \mathrm{FeCl}_{3}$ saturated solution. For the purpose of measurement, the antennas are connected to a $0.085^{\prime \prime}$ semi-rigid coaxial cable at the center of the ground plane. After adopting this feeding strategy, the measurement results became quite stable. The simulated and measured results for return loss are compared in Fig. 2. Good agreement is observed. The measured bandwidths are found to be $32 \%(1.54-2.14 \mathrm{GHz})$ at the $2-\mathrm{GHz}$ band, $9 \%$ (3.46-3.8 GHz) at the $3.5 \mathrm{GHz}$ band, and $17 \%(4.86-5.80 \mathrm{GHz})$ at the $5-\mathrm{GHz}$ band, respectively.

The radiation pattern of the triple-band antenna almost has no significant change over each frequency band. Therefore, we only plot the patterns at the center frequencies for each frequency band (i.e., $1.8 \mathrm{GHz}$ for the $2-\mathrm{GHz}$ band, $3.6 \mathrm{GHz}$ for the $3.5-\mathrm{GHz}$ band, and $5.4 \mathrm{GHz}$ for the $5-\mathrm{GHz}$ band). The radiation pattern in the $2-\mathrm{GHz}$ band has a figure-eight configuration in the $\mathrm{x}-\mathrm{z}$ and $\mathrm{y}-\mathrm{z}$ planes, and an omni-directional shape in the $x-y$ plane, similar to the radiation pattern of a dipole. The radiation pattern in the $3.5-\mathrm{GHz}$ band exhibits two main lobes in the $\mathrm{x}-\mathrm{z}$ and $\mathrm{y}-\mathrm{z}$ planes due to the 2nd-order mode excited in the two-strip monopole. The radiation pattern in the $5-\mathrm{GHz}$ band has three main lobes in the $x-z$ and $y-z$ planes due to the 3rd-order mode excited in the two-strip monopole. In the $2-\mathrm{GHz}$ band, the peak gain is found to be around $2 \mathrm{dBi}$ while in the $3.5-\mathrm{GHz}$ and $5-$ $\mathrm{GHz}$ bands the peak gain is increased to about $4 \mathrm{dBi}$ because of the increased directivity. The simulated radiation efficiency is higher than $95 \%$. (A conductivity of $\sigma=5.8 \times 10^{7} \mathrm{~S} / \mathrm{m}$ for the metal and a loss tangent of tan $\delta=0.0009$ for the dielectric substrate were used in the simulation.), which means that the triple-band planar antenna is a highly efficient radiator.

\section{CONCLUSION}

A triple-band low-profile planar antenna has been developed for wireless applications. The triple-band antenna has a height of only $8 \mathrm{~mm}$. It has been demonstrated that the low-profile planar antenna can achieve a bandwidth of $32 \%(1.54-2.14 \mathrm{GHz})$ at the 2GHz band, 9\% (3.46-3.8 GHz) at the $3.5 \mathrm{GHz}$ band, and $17 \%(4.86-5.80 \mathrm{GHz})$ at the 5-

$\mathrm{GHz}$ band. This antenna may find wide applications for mobile phones, WLAN, and WiMax handsets.

\section{Acknowledgement}

The authors wish to acknowledge the support of Georgia Electronic Design Center.

\section{References}

[1] K.-L. Wong, G.-Y. Lee, and T.-W. Chiou, "A low-profile planar monopole antennas for multiband operation of mobile handsets," IEEE Trans. Antennas Propagat., vol. 51, no. 1, pp. 121-125, Jan. 2003. 
[2] Y.-L. Kuo and K.-L. Wong, "Printed double-T monopole antenna for 2.4/5.2 GHz dual-band WLAN operations," IEEE Trans. Antennas Propagat., vol. 51, no. 9, pp. 2187-2192, Sept. 2003.

[3] J.-Y. Jan and L.-C. Tseng, "Small planar monopole antenna with a shorted parasitic inverted-L wire for wireless communications in the 2.4, 5.2, and 5.8-GHz bands," IEEE Trans. Antennas Propagat., vol. 52, no. 7, pp. 1903-1905, July, 2004.

[4] W.-C. Liu, W.-R. Chen, and C.-M. Wu, "Printed double S-shaped monopole antenna for wideband and multiband operation of wireless communications," IEE Proc.-Microw. Antennas Propag. vo1. 151, no. 6, pp. 473-476, Dec 2004.

[5] K.-L. Wong, L.-C. Chou, and C.-M. Su, "Dual-band flate-plate antenna with a shorted parasitic element for laptop applications," IEEE Trans. Antennas Propagat., vol. 53, no. 1, pp. 539-544, Jan. 2005.

[6] H. Nakano, Y. Sato, H. Mimak, and J. Yamauchi, "An Inverted FL antenna for dual-frequency operation,” IEEE Trans. Antennas Propagat., vol. 53, no. 8, pp. 2417-2421, Aug. 2005.

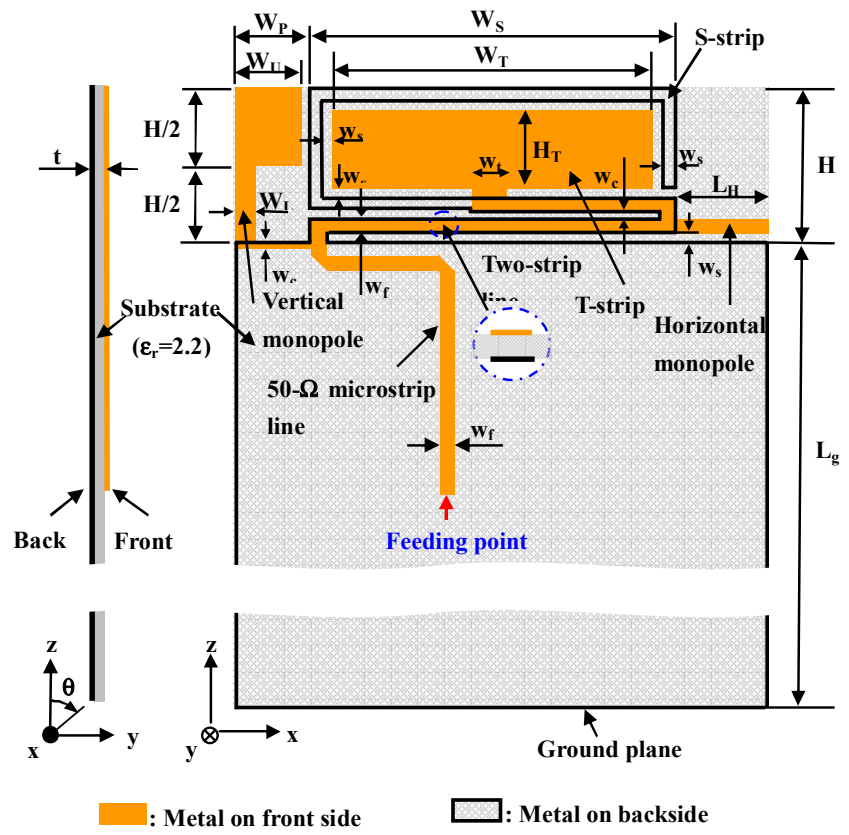

Fig. 1. Configuration of a triple-band low-profile planar antenna which consists of a two-strip monopole for the 2-GHz band, and a vertical monopole for the $5 \mathrm{GHz}$ band, and a horizontal monopole for the $3.5 \mathrm{GHz}$ band. (Geometrical parameters: $\mathrm{H}=8 \mathrm{~mm}, \mathrm{~W}_{\mathrm{S}}=19 \mathrm{~mm}, \mathrm{H}_{\mathrm{T}}=4.25 \mathrm{~mm}$, $\mathrm{W}_{\mathrm{T}}=17 \mathrm{~mm}, \mathrm{~W}_{\mathrm{P}}=4 \mathrm{~mm}, \mathrm{~W}_{\mathrm{U}}=3.5 \mathrm{~mm}, \mathrm{~W}_{\mathrm{L}}=1 \mathrm{~mm}, \mathrm{~L}_{\mathrm{H}}=6 \mathrm{~mm} \mathrm{w}_{\mathrm{s}}=0.5 \mathrm{~mm}, \mathrm{w}_{\mathrm{t}}=1.5 \mathrm{~mm}, \mathrm{w}_{\mathrm{c}}=0.25$ $\mathrm{mm}, \mathrm{w}_{\mathrm{f}}=0.75 \mathrm{~mm}, \mathrm{t}=0.254 \mathrm{~mm}$, and $\mathrm{L}_{\mathrm{g}}=60 \mathrm{~mm}$.)

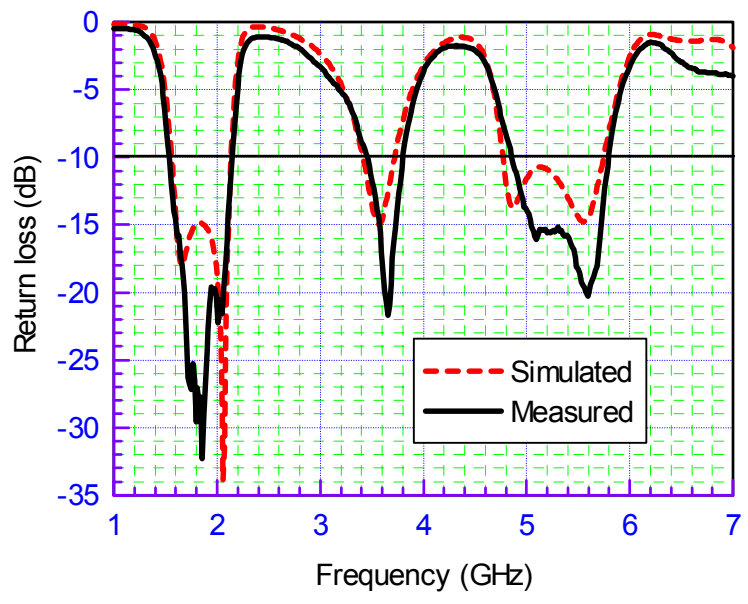

Fig. 2. Return loss of the triple-band planar antenna. 


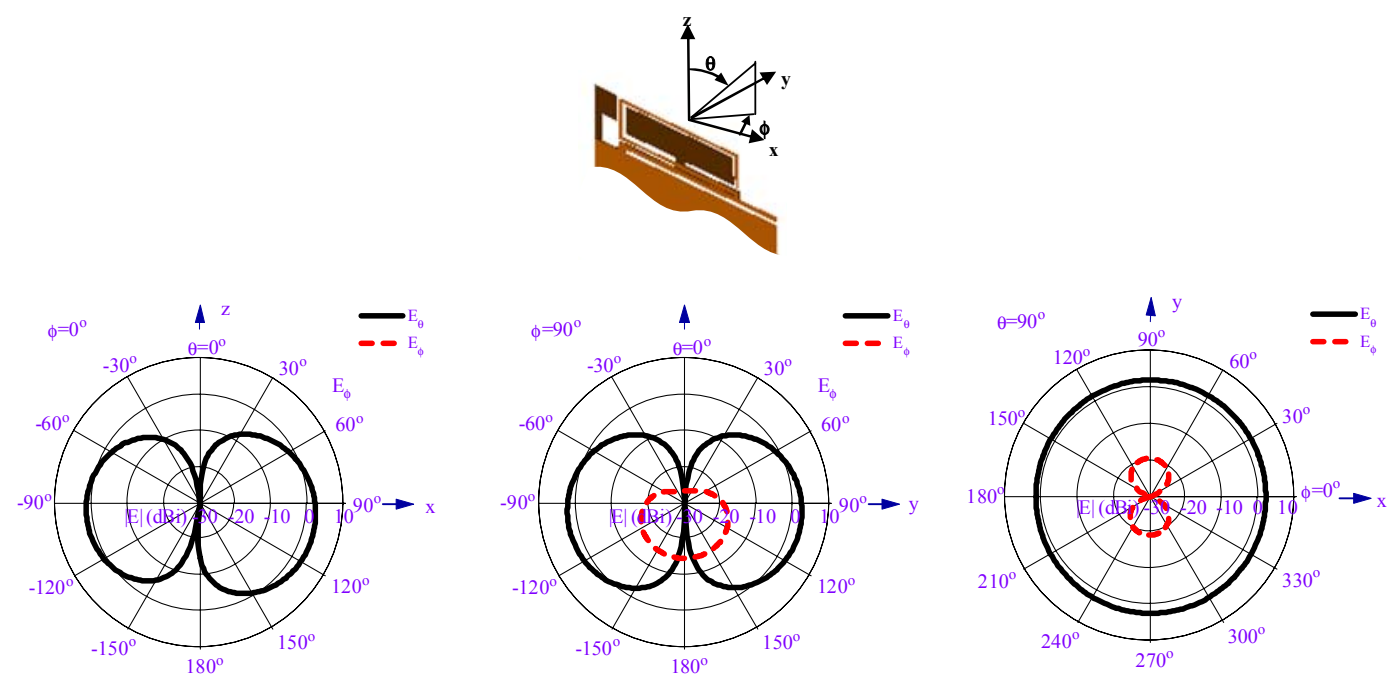

(a) $1.8 \mathrm{GHz}$
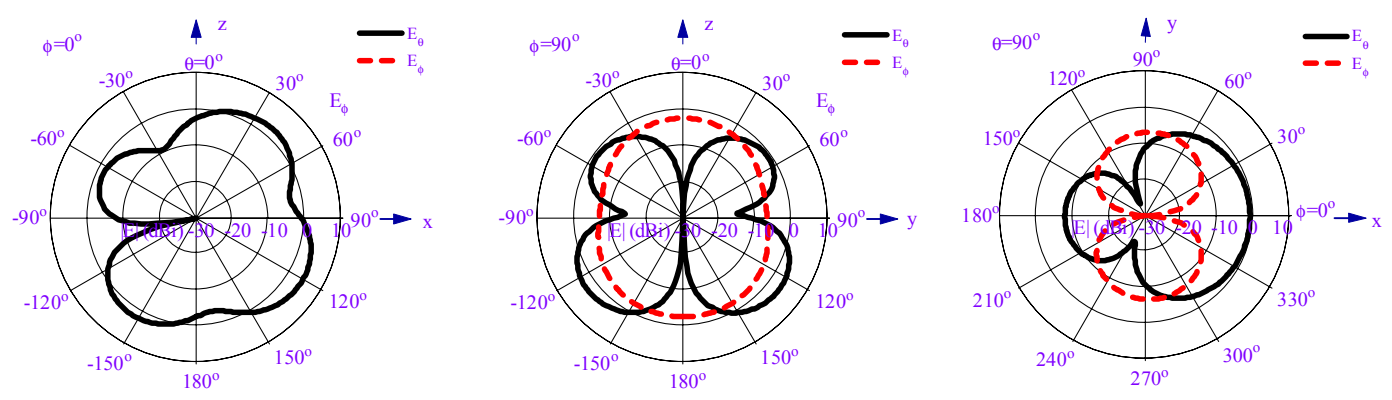

(b) $3.6 \mathrm{GHz}$
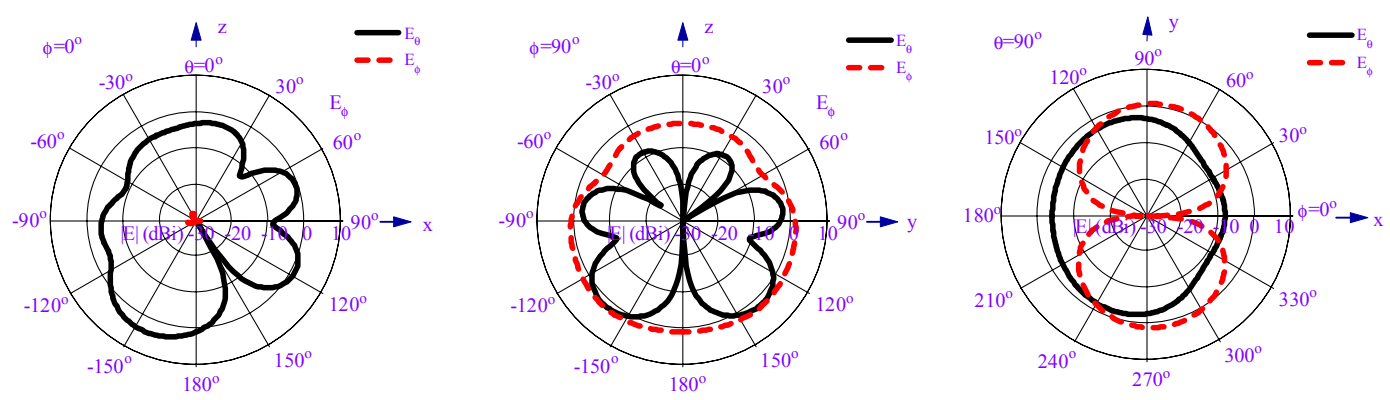

(c) At $5.4 \mathrm{GHz}$.

Fig. 3. Radiation patterns of the triple-band planar antenna. 